\title{
Crime displacement through formal surveillance
}

\begin{abstract}
The purpose of this systematic review is to find out to what extent the presence of formal surveillance ensures displacement or Diffusion of benefits of crime. The rational choice theory and routine activity theory supports the notion that crime is decreasing in the area where formal surveillance is present. Through the database Web of Science is using different search terms searched for studies that deal with displacement and positive diffusion of benefits through formal surveillance. Ten studies were included in this review. The majority of these studies show that there is a displacement effect, and/or positive radiation effect by the presence of formally monitoring. In particular, the studies that have used the most powerful methodology show a diffusion of benefits. This means that crime in the area with formal surveillance decreases, but also in adjacent areas thereof. This review has clearly identified the spatial effects of formal surveillance. For future studies of displacement and positive diffusion of benefits is advised to apply a WDQ analysis because the studies then more readily be compared with each other
\end{abstract}

Volume I Issue 3 - 2015

\author{
Lex Dekker \\ Faculty of Law, University of Leiden and VU University \\ Amsterdam, Netherlands
}

Correspondence: Lex Dekker, Faculty of Law, University of Leiden and VU University Amsterdam, Leiden, Netherlands, Tel 3I 627528533, Email lexdekker1993@gmail.com

Received: August 19,2015 | Published: October 21, 2015

Keywords: crime, formal surveillance, displacement, positive attitude

\section{Introduction}

A Systematic Review of Displacement and Diffusion Effects of Crime through Formal Surveillance from the nineties, CCTV deployed in public areas. ${ }^{1}$ Since then, several studies have calculated that in London at least hang half a million video cameras. ${ }^{1}$ This is roughly equivalent to an average of one camera for every fifteen people. Not only in London was from the nineties to see an increase in the number of cameras, but also in major cities in countries such as France and Spain. ${ }^{2}$ Camera surveillance is an example of formal surveillance, as well as for police patrols and alarm systems. ${ }^{3,4}$ According Weisburd et al., ${ }^{5}$ there is increasing evidence that various forms of formal surveillance impact in crime in and around the area of the intervention. For example, the risk that crime and nuisance move to areas with no intervention, in the sense of formal surveillance is present. The objective of formal surveillance is deterring offenders and potential offenders. This formal surveillance is accomplished through the use of actors who are primarily responsible for security, such as police officers and other security personnel. The introduction of technology, the above-mentioned actors helped or even replaced. For this reason, it is also to be placed under the term formal surveillance. ${ }^{6,7}$ According to the rational choice theory ${ }^{8}$ are offenders by committing formal surveillance deter crime. This theory states that because offenders and potential offenders weigh the costs and benefits of committing crime. The presence of formal surveillance increases the risk of getting caught. This increased risk of being caught, the costs are also increased, making the cost-benefit analysis is less favorable. Another criminological theory consistent with the deterrent effect of formal surveillance is routine activity theory of Cohen \& Felson. ${ }^{9}$ According to routine activity theory, the probability that a crime is committed greater when meet the following three conditions: lack of oversight, a motivated offender and suitable target. ${ }^{10}$ Sets the theory implied that if (formal) supervision is present in a public space, this deters offenders and potential offenders. With a public space, as in the article of Welsh Mudge \& Farrington, ${ }^{11}$ a space meant that one can make use of unencumbered and accessible for basically every citizen. The above criminological theories as Bernasco et al., ${ }^{12}$ compatible with the theory of situational crime prevention Clarke. ${ }^{13}$ This approach to prevention focuses on the potential target of a perpetrator. This target should be protected by formal surveillance which increases the probability of detection of the perpetrator. However itself, a number of situations occur when formal surveillance increases in a particular area, to ensure that formal surveillance not always lead to a reduction in overall crime. These situations indicate that crime in different ways can be moved as a result of an increase in formal surveillance in an area. ${ }^{14}$ Repetto $\mathrm{TA}^{15}$ outlined five types of crime displacement that may occur, which according to $\mathrm{Eck}^{16}$ spatial displacement is the most common variant. Bernasco et al., ${ }^{12}$ conclude that it is happening when adjacent areas experienced negative consequences from the implementation of formal surveillance. They call this the 'waterbed effect'. Another variation of displacement is that the perpetrator the moment when he commits an offense moved. Finally, distinguishes Repetto,${ }^{15}$ the following types of movement: the change of the type of crime, the change of the method of how the offender performs its offense and the change of target. Subsequently have Barr R et al., ${ }^{17}$ added a sixth category: perpetrator displacement. This will retain the offenses are committed, but by other offenders. In front of the negative situation that can arise, there is a situation defined as diffusion of benefits. ${ }^{6}$ This means that the preventive effect of formal surveillance has a reducing effect on the crime rate in adjacent areas. ${ }^{6}{ }^{18}$ This means that the intervention has a positive net effect in view of the reduction of the overall crime. ${ }^{19}$ This phenomenon can also be described on the basis of the waterbed effect. ${ }^{12}$ When pressure is applied on a water bed than by the resulting pressure will deform the entire water bed. Other terminology for diffusion of benefits is the multiplier effect of the bonus effect. ${ }^{20}$ Following the positive net effect put Bowers et al. ${ }^{19}$ that there may also be a negative net effect. This occurs when the displacement effect is greater than the degree to which the crime descends into the area of intervention. Returning to conclude the movement Sorg et al., ${ }^{21}$ that in addition to a normal displacement may lead to a reverse movement. This means that after the intervention increased crime in the areas of intervention and the crime decreases in the buffer and control areas.

This systematic review focuses on the causality between formal surveillance and the above described situations that may occur. Important to mention is that quite recently published three systematic reviews that are related to the topics that are discussed in this review. 
However, the published reviews are all measuring something other than what is examined in this review. Welsh et al., ${ }^{4}$ published a review which focuses specifically on the impact of CCTV on crime and Bowers et al. ${ }^{20}$ examined the effects of policing on crime. There is also a systematic review published on the effectiveness of security guards, place managers and defensible space on crime published by Welsh et al., ${ }^{11}$ An important difference with the previous reviews that this review will not be limited to one intervention, but all possible interventions in the form of formal surveillance have enrolled. The review of Farrington et al., ${ }^{4}$ and Bowers et al. ${ }^{20}$ by contrast to only one type of formal surveillance: one to one to CCTV and police surveillance. Added to that the review of Farrington et al., ${ }^{4}$ is about the causality between CCTV and crime reduction. Calculating displacement effects or diffusion of benefits belonged in this review not to the inclusion criteria. Finally comes the review of Welsh et al., ${ }^{11}$ as opposed to this systematic review primarily on informal and natural surveillance (security guards, place managers and defensible space). It is also calculated in this review not a displacement effect for all included studies. Apart from the fact that the three above reviews differ systematic review of these, in addition, the reviews are contradictory concerning the effects that arise due to the presence of forms of supervision. From the review of Farrington \& Welsh [4] shows that from the studies that measure or if there is displacement or diffusion of benefits are, these are not found in the majority of cases. The review of Welsh et al., ${ }^{11}$ a similar conclusion can be drawn, whether in the form of supervision varies between reviews. Bowers et al., ${ }^{20}$ however, concluded that police surveillance in more than half of the studies provides a displacement or diffusion of benefits of crime. In this systematic review, a detailed examination of whether the phenomenon is crime displacement or positive effect due to the presence of formal surveillance. This review therefore may paint a clear picture of the spatial effects of formal surveillance. The research question of this systematic review, therefore, is as follows: "Does the presence of formal surveillance in public areas result in crime displacement (or the displacement of crime)?"

\section{Methods}

\section{Search strategies}

The search process has taken place for this systematic review through the electronic database 'Web of Science'. The search has been used the option 'All Databases. This means that the individual citation databases are commonly searched. These separate citation databases are: 'Science Citation Index Expanded, "Social Sciences Citation Index and the Arts \& Humanities Citation Index. Relevant studies on crime displacement by the presence of formal surveillance sought by every logical combinations of the following search terms: formal surveillance; Displace*; *crime prevention*; *Displace crime; *situational crime prevention; *drug crime; hot spot policing; CCTV; security; diffusion of benefit*. When a search term behind an asterisk is placed, it means that there is searched for multiple words with a similar meaning. This provides greater results in the databases. An example is that in crime * searching on crime, criminal, criminality, et cetera. These searches are conducted in February and March 2014. Therefore, this review included articles published until March 2014. The time span in which 'Web of Science' is sought with the above terms ranging from 1990 to 2014. There has been chosen for the 1990 year, as from the nineties, one of the main forms of formal surveillance, namely CCTV, has been implemented.

\section{Search process}

The flow chart in Figure $1^{22}$ shows that the above terms totaling 259yielded results in the database Web of Science. All these items are then screened by title, with 33 articles as potentially relevant were judged. From these results, the abstracts were examined in order to assess whether the contents of the article, in all probability also met the inclusion criteria. Of these 33 articles were found seven still irrelevant to the question. Of the remaining 26 articles has been the full text. During the assessment of the studies showed there are some articles that did not meet the required design or research studies were no effective formal surveillance of a displacement or diffusion of benefits of crime. These are therefore excluded as well. Eventually, by this method remaining ten studies that will be discussed in this systematic review.

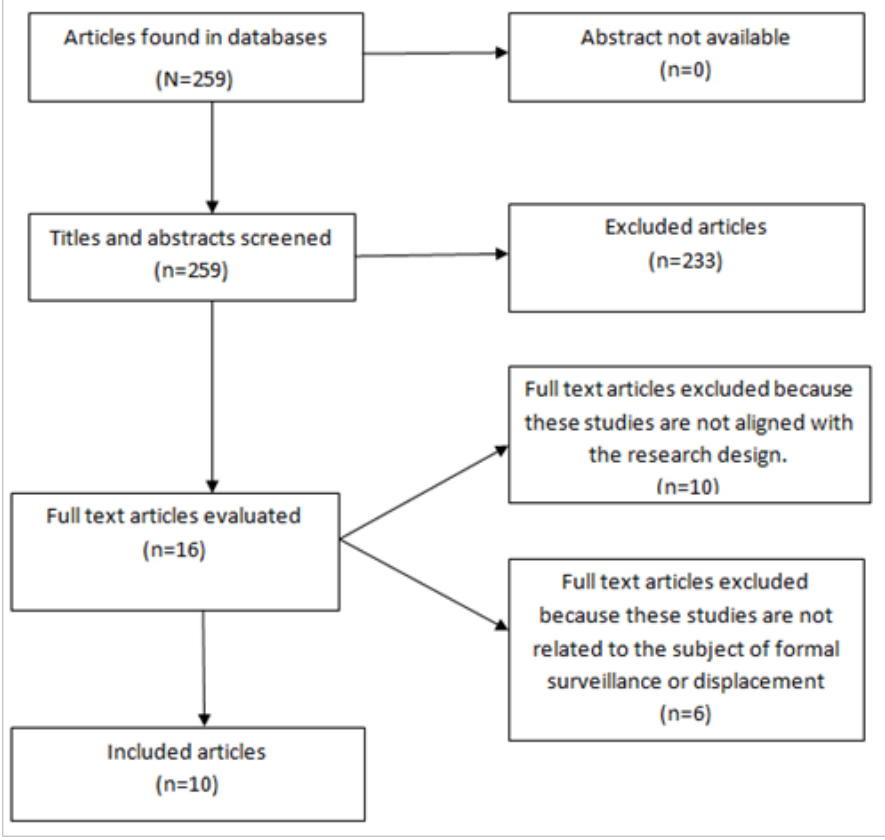

Figure I Flowchart of the search in web of science. ${ }^{22}$

Note: The numbers of counts are not completely, because at this stage the "Doubles" have not yet been removed.

\section{Inclusion criteria}

This systematic review examines the causality between formal surveillance and transfer or diffusion of benefits of crime. Examining a causal relationship in a systematic review means that only prospective studies should be included. There therefore has to be paid in the studies to the condition that there are on for measurement and post-measurement occurred. Research designs that meet this requirement are: quasi-experimental, quasi-experimental study with control impacts and finally experimental research. This then means that there minimum score of three must be met at 'The Maryland Scientific Methods Scale. ${ }^{23}$ Through including the studies that meet this minimum requirement concerning the research design can be determined whether there is indeed a causal link between the dependent and independent variable. These variables are in the systematic review respectively displacement/diffusion of benefits of crime and formal surveillance. The outcome of the studies must be a crime. This outcome is measured on the basis of crime statistics derived from quantitative data, such as police statistics, police calls and insurance data. Using this data, the changes between the studied areas could be compared. This is then determined whether there was a spatial displacement or diffusion of benefits. Spatial movement, together with diffusion of benefits is the biggest player 
in regards to the movements in crime can occur. On the other types of crime displacement is little (prospective) investigated. This is the reason why only spatial displacement is included as a form of crime displacement. To measure any displacement or diffusion of benefits were publications from all countries included where relevant research has been conducted. The only condition was that the study took place in a public space.

\section{Exclusion}

First studies with a cross-sectional study design included as exclusion. With cross-sectional studies, no causal link can be established between formal surveillance and spatial displacement or appearance of crime. A second exclusion have been added, are studies that have investigated in a different place than public areas. This exclusion has been added, as such more representative comparison can be made between the different studies. Moreover, it was expected that formal surveillance mainly affects offenses outdoors. Studies published in a language other than English or made available were also excluded because this systematic review it is not verifiable for everyone. Finally, all excluded studies that were published before the 2009 date, because the related systematic reviews from the introduction from 2009, 2010 and 2011 come. Two years 'overlap' is permitted in this review.

\section{Results}

Ten studies in this systematic review included to answer the research question "Does the presence of formal surveillance in public areas result in crime displacement (or the displacement of crime)?". In these ten studies investigated the response, in the sense of spatial displacement and diffusion of benefits, caused by the presence of formal surveillance in public space. Five of the studies go on CCTV and five go on one of the following forms of policing: police foot patrols, additional deployment of police and problem-oriented policing. The information and results of ten studies that met the inclusion criteria are summarized in Table 1. The studies lasted between one and two and half years. The studies examine not all the same crime the individual offense types, although the individual offense types of studies primarily with violent crimes and property crimes. With regard to the place of examination has taken place, the majority of the studies in the United States. Only two of the ten studies have been conducted outside the United States. Successively in Malaga (Spain) and Gwangmyeong (South Korea). Five studies used rational choice theory and/or routine activity theory to describe the effects of formal surveillance. The study of Copper et al.,24 on the other hand used the crackdown theory ${ }^{25}$ to explain the impact of police deployment. In the other four Studies have called a theory. The effects of formal surveillance have been determined on the basis of different methods. Five studies ${ }^{14,26-29}$ have used the Weighted Displacement Quotient [WDQ]. ${ }^{19}$ This is a commonly used method to measure a possible displacement or multiplier effect. For this method is experimental area, a buffer area required and a control area. The experimental area is the area in which the intervention is performed. The buffer area is the area that is located next to or around the experimental area. It is expected that crime can move or radiate toward the buffer zone. Finally, the control area make sure to see if the trend of further crime is stable and that it therefore has to be attributed to the intervention. It is not expected that crime will move or radiate to the control area. The WDQ analysis compares the change in the crime of these three areas with each other. Because use is made of both buffer areas such as the control areas is WDQ-analysis the most powerful method to determine whether or not there is one of the intended effects. Sorg et al., ${ }^{21}$ have established a reverse displacement on the basis of the Inverse Displacement Quotient (IDQ). The corresponding formula is similar to the formula used to determine the WDQ. The other studies ${ }^{2,24,30,31}$ have a displacement effect or multiplier effect based on the change of police statistics, police calls and insurance data of experimental sites, control areas and optionally buffer areas. The studies were grouped according to the way they measure the intended effects.

Table I A review of the studies in this systematic review.

\begin{tabular}{|c|c|c|c|c|c|}
\hline Study & City & Type of Crime & Intervention & Effects & Theory \\
\hline Caplan et al. ${ }^{26}$ & Newark & Shootings and Vehicle Crime & CCTV & Diffusion of Benefits & - \\
\hline Cerezo2 & Malaga & Almost all Criminality & CCTV & Displacement & - \\
\hline Copper et al. ${ }^{24}$ & Mesa & $\begin{array}{l}\text { Personal, Drug and Property } \\
\text { Crime }\end{array}$ & Policing Efforts & Displacement & Crackdown Theory \\
\hline Park et al. ${ }^{12}$ & Gwangmyeong & Robbery, Theft and Violent Crime & CCTV & diffusion of benefits & $\cdot$ \\
\hline Ratcliffe et al. ${ }^{27}$ & Philadelphia & $\begin{array}{l}\text { Capital,Violent and Drug Crime } \\
\text { Displacement }\end{array}$ & CCTV & $\begin{array}{l}\text { Diffusion of Benefits/ } \\
\text { Displacement }\end{array}$ & Rational Choice Theory \\
\hline Ratcliffle \& Breen ${ }^{28}$ & Camden & violence, power and drug crime & Policing Efforts & Diffusion of Benefits & $\begin{array}{l}\text { Rational Choice Theory \& } \\
\text { Routine Activity Theory }\end{array}$ \\
\hline Ratcliffe et al. ${ }^{29}$ & Philadelphia & violence Crime & Police on Foot & Displacement & Rational Choice Theory \\
\hline Reid \& Andrese ${ }^{3 !}$ & Surrey & Theft of and From Motor Vehicles & CCTV & $\begin{array}{l}\text { Diffusion of Benefits/ } \\
\text { Displacement }\end{array}$ & Rational Choice Theory \\
\hline Sorg et al. ${ }^{21}$ & Jersey City & $\begin{array}{l}\text { Violent and } \\
\text { Property Crime }\end{array}$ & Police on foot & Reverse Movement & - \\
\hline Taylor et al. ${ }^{30}$ & Jacksonville & $\begin{array}{l}\text { Violent and } \\
\text { Property Crime }\end{array}$ & $\begin{array}{l}\text { Problem Oriented } \\
\text { Policing }\end{array}$ & Displacement & Rational Choice Theory \\
\hline
\end{tabular}

Note: If no Data (-) are Presented in 'Theory', which Means, the Study no Explanation for the Observed Effect with or using a Particular Theory. 


\section{Studies with a WDQ analysis}

Five studies used a WDQ analysis to measure displacement effects and positive diffusion of benefits. The first study of Caplan et al., ${ }^{26}$ calculated a WDQ of .23 for shootings. For a car theft WDQ of . 78 was calculated. This implies that there was a small ripple effect through camera for shootings and presents a greater multiplier effect on car theft. Newark has CCTV so provided both shootings and car theft for a positive net effect on crime. This means that CCTV except in the intervention area, including the adjacent areas allows for a reduction in shootings and car theft. In the area of intervention hung 73 cameras. Compared with the other studies, this is a large amount of cameras. Moreover, there is made use of the powerful WDQ analysis. The study of Park et al., ${ }^{14}$ has calculated for both control areas in Gwangmyeong a WDQ. For one control area is a WDQ of .38 and calculated in a control area two WDQ of .41. Both values are between 0 and 1 . This means that CCTV has cause to do a diffusion of benefits. In this study, as in the study by Caplan et al. ${ }^{26}$ there is a net positive impact of the intervention. This means that adjacent areas benefit from the presence of CCTV in the intervention area. Indeed, there is seen a decrease in crime in both the intervention, as in the adjacent areas. The number of cameras that hung in this area of intervention was 23 . Ratcliffe et al., ${ }^{27}$ showed four of the eight areas examined in Philadelphia that CCTV had no effect on crime. In the other four sites, there was displacement and diffusion of benefits of total crime (light and serious crime together). At one location was a WDQ of -1.11 . This value means that the displacement effect is greater than the extent to which crime descends into the area of intervention. This in turn means that there is a negative net effect of the intervention. So there is more crime after the intervention with CCTV. In another location, there was also set a displacement effect, but this effect was smaller than the extent to which the crime is dropped into the area of intervention. The WDQ in this case was -0.43 . In the other two sites positive diffusion of benefits have been established; namely WDQ's 0.43 and 0.51 . These last two values are close to the values that Caplan et al., ${ }^{26}$ and Park et al., ${ }^{14}$ calculated in the studies. A limitation of this study is that in a number of experimental fields a very low frequency (monthly) of serious crime. At one location, for example, occurred only twice a form of serious crime in a month. This makes the data on total crime less valuable. However, for both light and serious crime also created a separate WDQ analysis. This can be considered a representative picture for the change of light on this crime as many figures are available. The accompanying WDQ's light crime: $-3.45,-0.21,0.48$ and -2.27 . Thus, where only light of crime would be assumed, there is at two locations (WDQ's of -3.45 and -2.27), there is a displacement that is greater than the reducing effect in the target area (negative net effect). At one location, the movement is smaller than the reducing effect (a WDQ of -0.21), and finally there is one place there is a diffusion of benefits that is smaller than the reducing effect in the target area (a WDQ of 0.48 ). In this area of intervention hanging a total of 18 cameras. Ratcliffe et al., ${ }^{28}$ have investigated in Camden. There is a WDQ calculated for the period for the intervention versus the period after the intervention. In addition, there is also a WDQ calculated for the period for the intervention versus the period during intervention. The WDQ at successively 0.69 and -0.32 . But after the intervention period. Compared with pre-intervention period, there actually is a diffusion of benefits. This diffusion of benefits effect is similar to the drop in crime in the area of intervention. Especially in violent crime, there is a strong positive multiplier effect after the intervention compared with before the intervention. In short, extra police deployment ensures reduction in crime in both the intervention area, and in adjacent areas.
Ratcliffe et al. ${ }^{29}$ have studied in Philadelphia and calculated a WDQ of -0.41 . This value indicates that foot patrols lead to displacement effects. However, these displacement effects are less significant than the degree to which the crime falls in the intervention area. This then means that foot patrols of the police, despite the displacement effects, yet ensure a reduction in overall crime. It is noteworthy that this is the only study with a WDQ-analysis, wherein is found a displacement effect alone. Other studies with a WDQ analysis show mostly diffusion of benefits. One explanation for this deviant outcome may be that the study of Ratcliffle et al., ${ }^{29}$ only takes violent crimes in their WDQ analysis.

\section{Studies with a different methodology than the WDQ analysis}

Five studies used a different method than the WDQ analysis to measure the displacement effects and positive diffusion of benefits. The first study of Sorg et al., ${ }^{21}$ finds an inverse displacement of crime in New Jersey. Three months after the intervention increased crime in the experimental areas by $1 \%$, while the crime rate decreased in the control areas by about $5 \%$ and decreased by almost $15 \%$ in the buffer zones. The accompanying IDQ is -0.43 . This means that after police foot patrols just to see an increase in crime in experimental areas and that the crime in the buffer and control areas with decreased to a greater extent as compared with before the intervention. Cerezo ${ }^{2}$ compares in Malaga changes in crime between the experimental areas and control areas. Here too there has been a pre- and posttest. In general it can be said that the crime rate has barely diminished by the camera equipment $(-1.9 \%)$ in the streets where they are posted. In the neighboring areas is just a sharp increase in crime observed $(+14.6 \%)$. This indicates Cerezo according to a displacement of crime. This movement is in accordance with Cerezo caused by the installation of cameras. This conclusion is drawn quickly, because the crime rate in the control region with its own sheep same as the area with CCTV also increases sharply $(+11.1 \%)$. This indicates possible that crime anyway rose between 2006 and 2008. The increase in the adjacent streets of camera is not necessarily just the result of a displacement effect. This study has all the necessary information to calculate a WDQ and thus had the changes in the intervention, buffer and control areas can be compared. In this study, use was made of the smallest number of cameras ${ }^{17}$ to measure a displacement effect. Copper et al., ${ }^{24}$ compared to standard Mesa police patrol strategies with short-term police patrols. The brief police patrols led to a decline in the experimental area, but at the same time a temporary spatial displacement to adjacent areas. In the adjacent areas the crime increased by the same degree as he fell in the experimental area. The data are compared before and after the intervention on the basis of the number of police calls. On average, the number of police calls related crime increased by $5 \%$ in the adjacent areas. The number of reports of nuisance crime has actually increased by $10 \%$ after the intervention. With respect to car theft, however, is no displacement effect observed. Police calls for vehicle theft decreased in the intervention area, but in adjacent areas could see no change. Taylor et al., ${ }^{30}$ studied in Jacksonville whether there has been a displacement effect or multiplier effect through the use of problem-oriented policing. This has been investigated by comparing the change in crime, the buffer areas and control areas with the police statistics and police calls. The comparison between the areas has taken place both before and after deployment of the problemoriented policing. The Uniform Crime Reporting [UCR] data show no statistical changes before and after the intervention. According to these data so is to establish no displacement effect or multiplier effect. 
However, there can be seen a greater increase in the number of police calls in the neighboring areas of the area of intervention than in the control areas. This would be in contrast to the UCR-well data may be indicative of a displacement effect. The data speak thus against each other and this makes it difficult to make a valuable decision based on this study. Reid et al., ${ }^{31}$ investigated whether auto-related crime is changing through the use of camera surveillance in a parking garage. To determine a possible displacement effect, there looked at the crime alteration of the adjacent districts of the car park in Surrey. The crime rate change is measured on the basis of a pre-and post-treatment in the different areas. Use has been made of police statistics, Police Records Information Management Environment for British Columbia (PRIME-BC). Also been used insurance data (ICBC). PRIME-BC data showed no significant changes between pre- and post. From ICBC data shows that motor vehicle crime does not change during the intervention, but only after the intervention. This change is a decrease. The neighboring district of North Delta shows no change in the theft of motor vehicles. The district Whalley other hand, exhibits a decline, which could indicate a diffusion of benefits. In the district of Guilford crime actually increases after the implementation of CCTV in the car park. This indicates crime displacement. Finally, in South Surrey a large increase in motor vehicle theft adopted after the installation of the cameras. This seems at first sight to crime displacement. The researchers, however, that given the distance between the garage and the district of South Surrey is unlikely to change in South Surrey by the intervention occurred. The ICBC data appear to be no significant changes occurred in the theft of motor vehicles. This research has yielded many non-significant results. This allows the study weaker to make valuable statements, because non-significant results may also simply indicate that there is no consistency.

\section{The WDQ analysis versus other methods}

After analyzing the results of the included studies show that formal surveillance exercised influence on crime. In all studies, the effect has been observed on the spatial displacement or diffusion of benefits. When two ${ }^{30,31}$ of the ten studies, the displacement and diffusion of benefits is less clear, because in these two studies are different databases that contradict each other. According to police statistics, there is no question of any displacement or diffusion of benefits. If the number of police calls ${ }^{30}$ or insurance data ${ }^{31}$ is assumed, there is talk of displacement ${ }^{30}$ and positive emission. ${ }^{31}$ The effects found in these two studies are not consistent and therefore less clear. It is also striking that studies with a WDQ analysis have found mostly positive diffusion of benefits resulting from the implementation of formal surveillance. Studies using other methods than a WDQ-analysis in order to determine displacement or knock-on effects, mainly conclude that there are displacement effects created by the presence of formally monitoring. The WDQ analysis is the most powerful method in order to establish the above effects. This means that the results of studies with WDQ analysis are probably more valuable to make statements about displacement and positive attitude than studies that use a different method.

\section{Discussion}

In this systematic review was to examine whether there is displacement effects and/or positive diffusion of benefits from the presence of formal surveillance. Ten studies were selected for the research question "Does the presence of formal surveillance in public areas and the displacement of crime?" Answer. The analysis of the results shows that the majority of the included studies established a clear displacement effect or a diffusion of benefits. Based on these results it can be concluded that the presence of formal surveillance leads to a displacement or diffusion of benefits of crime. However, the studies do not show all relevant results. This is possible in the research methodology. It is striking that studies show have used a WDQ analysis generally results other than studies that did not use here. The studies with a WDQ-analysis concluded that there is only a diffusion of benefits, or that this effect occurs to a greater extent than the displacement effect. An exception is the study of Ratcliffle et al., ${ }^{28}$ They conclude, just as the studies using a different methodology than a WDQ analysis that formal surveillance ensures a displacement of crime. One explanation for the exception to the conclusion of Ratcliffle et al. ${ }^{28}$ may be that this study only violent crime included in the study. According to Woodworth et al., ${ }^{32}$ namely violent crimes committed very impulsive. This would mean that formal surveillance has less impact on violent crime, as perpetrators of this crime less weigh to commit an offense. In contrast, the study does show that crime in greater falls in the intervention area than that crime is rising in the adjacent areas. One explanation is that police foot patrols even for impulsive offenders as a deterrent. As indicated earlier in this systematic review, the WDQ analysis is methodologically strongest way to determine a displacement effect or diffusion of benefits. This means that the results of studies that have used the WDQ analysis are the most valuable. More than three quarters of the studies used a WDQ analysis shows a diffusion of benefits. When using these methodologically strongest studies to answer the research question must be given, it seems that the presence of formal surveillance creates a positive ripple effect of crime. The crime rate not only falls in the area with formal surveillance, but also in adjacent areas thereof. To explain the spatial effects of formal surveillance can be used a number of criminological theories. The rational choice theory ${ }^{8}$ and the routine activity theory ${ }^{9}$ are discussed in the introduction to explain displacement effects and positive diffusion of benefits. Half of the studies $^{27-30}$ describe the potential effects of the presence of formal surveillance with the aid of at least one of these two theories. Copper et al., ${ }^{24}$ however, use the crackdown theory to explain the impact of police deployment. This theory states that the probability of the occurrence of crimes is enhanced by the rotation frequency and of short-term police patrols. ${ }^{25}$

In the other studies, there is no explicit mention of a theory to explain the effects. Well spoken in these studies about terms such as deterrence. Perpetrators are demotivated and discouraged to commit crime when the perceived risk of being caught is increasing. ${ }^{33}$ The presence of formal surveillance will except the real risk of being caught, even the perceived risk of being caught increase. This deterrence mechanism increases the cost of committing crime. Despite the rational choice theory is not mentioned literally, the effects would be from the criminological theory can be argued. According to the rational choice theory and routine, the presence of formal surveillance for a reduction in crime in the area of intervention. A possible interpretation for the diffusion of benefits is that offenders and potential offenders wrongly perceive the scope of the formal surveillance. This means that they have been given the false impression that the formal surveillance in the area where they are criminally active, also focuses on neighboring regions. ${ }^{12}$ This systematic review has clearly outlined image on the spatial effects of crime through formal surveillance. The results of this systematic review, however, are very different with respect to the results of the review by Welsh et al., ${ }^{4}$ and the review of Welsh et al., ${ }^{11}$ 
These researchers concluded because unlike this review that there was rarely any question of a diffusion of benefits. Bowers et al., ${ }^{20}$ however, came to the conclusion that a displacement or diffusion of benefits is more common than that nothing will change on crime in the adjacent areas. This review has shown that there is almost always there is a displacement or multiplier effect. Such information may be used by other government agencies and other security companies considering the use of formal surveillance, but doubts about the reduction of total crime. The conclusion of this systematic review will be able to be decisive in this case of doubt, in order still to make use of one or more types of formal surveillance in public areas. Despite the fact that this systematic review has scooped a clear picture of the spatial effects of formal surveillance, the review contains a number of limitations. The first limitation is that it uses only the database Web of Science 'and that there is a pre-established criterion for the number of studies could be included. This criterion is set at a minimum of ten and a maximum of fifteen studies. By adding these restrictions are probably a number of valuable studies have not found in the search process. Alternatively it can be an advantage to find articles from studies in the database Web of Science ', because in this database is to find many articles and his only peer-reviewed articles. A second limitation is that not all included studies have calculated the same way displacement effects or spillovers. When it would have been the case, had the studies in this systematic review mutual probably be better compared. Now it is not entirely clear whether the difference in the results is due to the method of calculation, or by other differences in the studies.

It is advisable to take these factors relating to limitations in future research. By using multiple databases, a larger number of studies were found on the examined phenomenon of this systematic review going. Also, future studies that investigate displacement effects and positive spillovers crime advised to use a WDQ analysis. In this way can in the future appear a systematic review only a study with a WDQ analysis is included. As a result, the results can be better compared with each other, so that the question is removed or if any differences are situated in the method of measuring. The recommendations listed above, relate in particular to similar future research on the displacement and diffusion of benefits of crime. Another suggestion for future research on the physical side effects of crime through formal surveillance is to make more comparisons during the investigation. This could be by looking at whether certain continents, countries, cities or even neighbourhoods are differences in the degree of displacement and the diffusion of benefits are present. Or by specifically looking at how the strength of the displacement or diffusion of benefits effect varies between different types of crime. This systematic review has shown that the presence of formal surveillance in public areas and the adjacent areas to benefit from the crime reduction. The presence of formal surveillance ensures therefore almost always a reduction in crime. If a displacement effect is already established, this is often smaller than the extent to which the crime decreases in the area of intervention. Formal surveillance is hence a good form of crime prevention.

\section{Acknowledgments}

None.

\section{Conflicts of interest}

The author declares that there are no conflicts of interest.

\section{References}

1. Wood DM. The surveillance society Questions of history, place and culture. European Journal of Criminology. 2009;6(2):179-194.
2. Cerezo A. CCTV and crime displacement: A quasi-experimental evaluation. European Journal of Criminology. 2013;10(2): 222-236.

3. Welsh BC, Farrington DP. Effects of closed-circuit television on crime. Annals of the American Academy of Political and Social Science. 2003;587(1):110-135.

4. Welsh BC, Farrington DP. Public area CCTV and crime prevention: An updated systematic review and meta-analysis. Justice Quarterly. 2009;26(4):716-745

5. Weisburd D, Wyckoff LA, Ready J, et al. Does crime just move around the corner? A controlled study of spatial displacement and diffusion of crime control benefits. Criminology. 2006;44(3):549-591.

6. Clarke RV, Weisburd D. Diffusion of crime control benefits: observations on the reverse of displacement, Crime prevention studies. Criminal Justice Press Monsey, USA. 1994;165-193.

7. Cozens P, Saville G, Hillier D. Crime prevention through environmental design (CPTED): A review and modern bibliography. Property Management. 2005;23(5):328-356.

8. Cornish DB, Clarke RV. The reasoning criminal: rational choice perspectives on offending. Springer-Verlag, New York, USA. 1986;246.

9. Cohen LE, Felson M. Social change and crime rate trends: A routine activity approach. American Sociological Review. 1979;44(4):588-605.

10. Felson M. Routine activity approach as a general crime theory. In: E McLaughlin et al., editors. Criminological Perspective, 2nd edition. London, England, Sage. 2003;160-168.

11. Welsh BC, Mudge ME, Farrington DP. Reconceptualizing public area surveillance and crime prevention: Security guards, place managers and defensible space. Security Journal. 2010;23:299-319.

12. Bernasco W, Elffers H, Bruinsma G. The waterbed effect. Spatial effects of territorial measures against crime. Journal of Criminology. 2006; $48: 243-258$.

13. Clarke RV. Situational crime prevention: Successful case studies, 2nd edn. Harrow and Heston, Albany, New York, USA. 1997;1-47.

14. Park HH, Oh SG, Paek SY. Measuring the crime displacement and diffusion or benefit effects of open-street CCTV in South Korea. International Journal of Law Crime and Justice. 2012;40(3):179-191.

15. Repetto TA. Crime prevention and the displacement phenomenon. Crime and Delinquency. 1976;22(2):166-177.

16. Eck JE. The threat of crime displacement. Problem Solving Quarterly. 1993;6(3): $1-7$

17. Barr R, Pease K. Crime placement, displacement, and deflection. In: Michael Tonry et al., editors. Crime and Justice: A Review of Research. University of Chicago Press, USA. 1990;12: 277-318.

18. Green L. Cleaning up drug hot spots in Oakland, California: The displacement and diffusion effects. Justice Quarterly. 1995;12(4):737-754.

19. Bowers JK, Johnson SD. Measuring the geographical displacement and diffusion or benefit effects of crime prevention activity. Journal of Quantitative Criminology. 2003;19(3):275-301.

20. Bowers KJ, Johnson SD, Guerette RT, et al. Spatial displacement and diffusion of benefits among geographically focused policing initiatives: A meta-analytical review. J Exp Criminol. 2011;7(4): 347-374.

21. Sorg ET, Haberman CP, Ratcliffe JH, et al. Foot patrol in violent crime hot spots: The longitudinal impact of deterrence and posttreatment effects of displacement. Criminology. 2013;51(1):65-102.

22. Moher D, Liberati A, Tetzlaff J, et al. PRISMA Group. Preferred reporting items for systematic reviews and meta-analyzes: the PRISMA Statement. PLoS Med. 2009;6(7):e1000097. 
23. Farrington DP, Gottfredson DC, Sherman LW, et al. The Maryland Scientific Methods Scale. In: LW Sherman et al., editors. Evidencebased crime prevention. Routledge, USA. 2002;13-21.

24. Copper CS, Taylor RB, Woods DJ. A randomized test of initial and residual from deterrence directed patrols and use of license plate readers at crime hot spots. Journal of Experimental Criminology. 2013;9(2):213-244.

25. Sherman LW. Police crack downs: Initial and residual deterrence. In: M Tonry et al., editors. Crime and Justice: A Review of Research. University of Chicago Press, USA. 1990;12:1-48.

26. Caplan JM, Kennedy LW, Petrossian G. Police-monitored CCTV cameras in Newark, NJ: A quasi-experimental test or crime deterrence. Journal of Experimental Criminology. 2011;7(3):255-274.

27. Ratcliffe JH, Taniguchi T, Taylor RB. The crime reduction effects or public CCTV Cameras: A multi-method approach spatial. Justice Quarterly. 2009;26(4):746-770.

28. Ratcliffe $\mathrm{JH}$, Breen C. Crime diffusion and displacement: Measuring the side effects or police operations. The Professional Geographer. 2011;63(2):230-243
29. Ratcliffe JH, Taniguchi T, Groff ER, et al. The Philadelphia Foot patrol experiment: A randomized controlled trial of police patrol effectiveness in violent crime hotspots. Criminology. 2011;49(3):795-831.

30. Taylor B, Copper CS, Woods DJ. A randomized controlled trial of different policing strategies at hot spots of violent crime. Journal of Experimental Criminology. 2011;7(2):149-181.

31. Reid AA, Andresen MA. An evaluation of CCTV in a car park using police and insurance data. Security Journal. 2014;27:55-79.

32. Woodworth M, Porter S. In cold blood: Characteristics of criminal homicides as a function of psychopathy. Journal of Abnormal Psychology. 2002;111(3):436-445.

33. Ratcliffe JH. Video surveillance of public places. Center for Problem Oriented Policing, Washington, USA. 2006;1-100. 